\title{
Mutual Shaping of Users and Technologies in a National Virtual Community
}

\author{
By Pablo J. Boczkowski
}

In this essay I analyze how technologies and users relate to each other in a national virtual community. I argue that a mutual shaping perspective is best suited to capture the complexity, unpredictability, and recursivity of the interactions among technological features and users' discourses and practices. Drawing from recent developments in the study of computer-mediated communication, multidisciplinary technology scholarship, and social psychology of nationhood, I show the mutual shaping of hardware capabilities, national identities, collective remembering, software configurations, and coordination practices that took place during my investigation of the Argentine Mailing List.

People have migrated for centuries. Those who have desired to remain in contact with their places of origin have relied heavily upon communication technologies. In this sense, migrants have used material objects such as letters, newspapers, telephones, and television sets to reconstruct what it means to be a member of a territorially, historically, and culturally located community in situations of geographical displacement. More recently, émigrés have increasingly used various forms of computer-mediated communication (CMC) to accomplish this goal. One intriguing way in which this phenomenon has taken shape is in the outcropping of national virtual communities: Mailing lists and bulletin boards where migrants have regular exchanges with their fellow nationals, almost always about issues linked to their nationalities and their migration experiences (Li, 1990; Mitra, 1996; Ogan, 1993; Rai, 1995).

National virtual communities are not purely social or purely material entities. They are ensembles of technological features and users' practices such as hardware configurations, relational patterns, software choices, "netiquette" rules, tele-

\footnotetext{
Pablo Boczkowski (MA, Cornell University, 1997) is a PhD candidate in the Department of Science and Technology Studies at Cornell University. His research interests include social studies of computermediated communication. The author is grateful for the help of Zonja, Ores, and El Carcamán, and many other members of the Argentine Mailing List during the research process. He would also like to acknowledge the valuable contributions of Ben Anderson, Simon Cole, Ken Gergen, Stefan Helmreich, Stephen Hilgartner, Sheila Jasanoff, Ron Kline, Irina Konstantinovsky, Bruce Lewenstein, Christina Lindsay, Sheila McNamee, Trevor Pinch, Peter Taylor, J. Paul Yarbrough, and Noah Zatz, and of seminar participants at Cornell University and the Massachusetts Institute of Technology.
} 
communications infrastructures, and national traditions. Thus, a question emerges: How do technologies and users relate to each other? In this essay I argue that users shape the artifacts they interact with, in, and through as much as vice versa. Drawing from recent developments in social studies of $\mathrm{CMC}$, multidisciplinary technology scholarship, and social psychology of nationhood, I show the mutual shaping of hardware capabilities, national identities, processes of collective remembering, software configurations, and coordination practices that took place during my investigation of the Argentine Mailing List (AML), which is a national virtual community composed mostly of Argentine people living abroad.

First, I depict the theoretical developments that informed my investigation. Second, I outline the research site and the methods employed to examine it. Then, I describe the results of the study. Finally, I reflect on their broader implications and speculate about potential venues for further inquiry.

\section{Theoretical Considerations}

This essay emerges at the crossroads of three contexts of inquiry: social studies of CMC phenomena, multidisciplinary examinations of technological change, and social psychological analyses of nationhood. Each of these contexts furnishes conceptual tools to address complementary aspects of the technology-user relationship in the AML. The CMC literature provides insights on the dynamics of that relationship in the case of computer devices used for communication purposes. The scholarship on technological change places those insights within more general developments on how humans and machines relate to each other. Finally, the social psychological study of nationhood frames the above-mentioned contributions within the specifics of a virtual community where membership is driven strongly by a special interest in national issues.

\section{Social Studies of Computer-Mediated Communication}

In recent times the use of computers to communicate has blossomed and so have the efforts to understand the social dimensions of these phenomena. As a result of that research, a host of conceptual frameworks has originated. Because they have been assessed elsewhere (e.g., Baym, 1995; Fulk \& Boyd, 1991; Garton \& Wellman, 1995; Rice, 1992; Steinfield, 1992; Walther, 1996), I concentrate on one aspect of these frameworks: their treatment of the technology-user relationship.

A first set of frameworks has posited that particular technological features have a direct impact upon social processes. For example, authors working under the reduced-cues model (Dubrovsky, Kiesler, \& Sethna, 1991; Finholt \& Sproull, 1990; Kiesler \& Sproull, 1992; Siegel, Dubrovsky, Kiesler, \& McGuire, 1986) have argued that the lack of nonverbal information in electronic-mail exchanges leads to antisocial behavioral patterns such as "flame wars." Other major representatives of this way of thinking have included information richness theory (Daft \& Lengel, 1986; Daft, Lengel, \& Trevino, 1987; Trevino, Lengel, Bodensteiner, Gerloff, \& Muir, 1990) and social presence theory (Short, 1974; Short, Williams, \& Christie, 1976). Despite the differences among them, the proponents of direct-impact per- 
Analytic focus

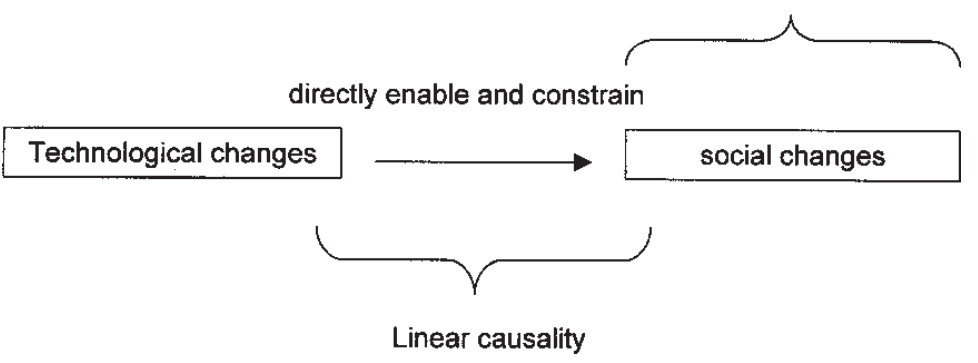

Figure 1. Direct-impact conceptualizations: relationships among the elements, forms of causality, and focus of the analysis

spectives have shared a key metatheoretical notion: a concrete aspect of CMC systems is said to generate a given set of social responses on which the analysis should focus (see Figure 1).

Reactions against some limitations of these frameworks have generated a new set of approaches. These limitations have become manifest in the emergence of unintended and unanticipated outcomes, and in the occurrence of different effects produced with the adoption of the same technologies by diverse social groups. If particular technological features were supposed to have particular social consequences, how do we explain unintended, unanticipated, and differential results? To remedy these inconsistencies, authors working with this second set of theories have proposed that the impact of technology upon society is not direct but mediated (Fulk, Steinfield, Schmitz, \& Power, 1987; Kling \& Scacchi, 1982; Markus, 1987; Poole \& DeSanctis, 1990; Spears \& Lea, 1992). For example, adaptive structuration theory researchers have argued that "the impacts of the technology on group outcomes depend upon: the structural potential of the technology[;] . . how technology and other structures . . . are appropriated by group members; and what new social structures are formed over time" (DeSanctis \& Poole, 1994, p. 143). In sum, mediated-impact perspectives have conceived the introduction of new technologies as provoking individual or collective processes, or both, that can yield outcomes different than those initially planned and that can recursively impact upon these very same mediation processes (see Figure 2).

Despite the differences between direct- and mediated-impact approaches, these approaches have shared one general goal: to explain the effects CMC systems have on social phenomena. Even those frameworks that have taken into account how technology is socially shaped, have restricted the treatment of this process to the design and development stages. However, as early as 1987, Rice pointed to the importance of "reinvention" of CMC tools in their context of use. More recently, several scholars have begun to furnish empirical and conceptual accounts of these reinvention processes (Feenberg, 1993; Jackson, 1996; Lea, O'Shea, \& Fung, 1995; Lea \& Spears, 1995). According to these perspectives, technological 


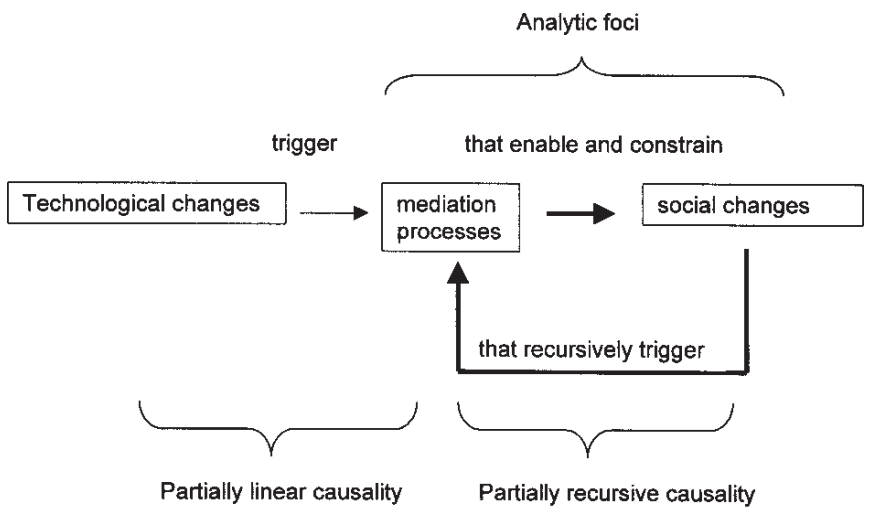

Main differences with Direct Impact perspectives.

Figure 2. Mediated-impact conceptualizations: relationships among the elements, forms of causality, and foci of the analysis

changes trigger mediation processes that yield social outcomes that might recursively affect the very technologies and mediation processes that generated those initial social outcomes ${ }^{1}$ (see Figure 3). This line of inquiry has been perhaps most clearly expressed in the work of Orlikowski and her colleagues (Orlikowski, 1992; Orlikowski \& Robey, 1991; Orlikowski \& Yates, 1994; Yates \& Orlikowski, 1992), who have argued that CMC phenomena emerge from an interplay among technological features and users' actions in which all the entities at stake have the potential to influence each other at some point during the unfolding of their relationships. For example, in a study of a computer conferencing system, Orlikowski and her associates found that a group of users affected the coevolution of CMC devices and users' practices by assisting other users to deal with these tools. Thus, that group "shaped both users' understandings of the technology and the technology itself to keep news-system usage more effective and relevant" (Orlikowski, Yates, Okamura, \& Fujimoto, 1995, p. 434).

This brief review of the literature in the social study of CMC shows that the initial focus on technology's impact upon modes of use has been recently challenged by developments that demonstrate that users transform, and not only adapt

\footnotetext{
${ }^{1}$ Even direct-impact scholars such as Sproull and Kiesler (1991) have made statements congenial with this mutual shaping view of technology-in-use. For example, they argued that "second-level," unanticipated system-wide effects "are not caused by technologies operating autonomously on a passive organization or a society. Instead, they are constructed as technology interacts with, shapes, and is shaped by the social and policy environment" (p. 8). However, most of that book was devoted to examining technology's direct and mediated impact upon organizations.
} 


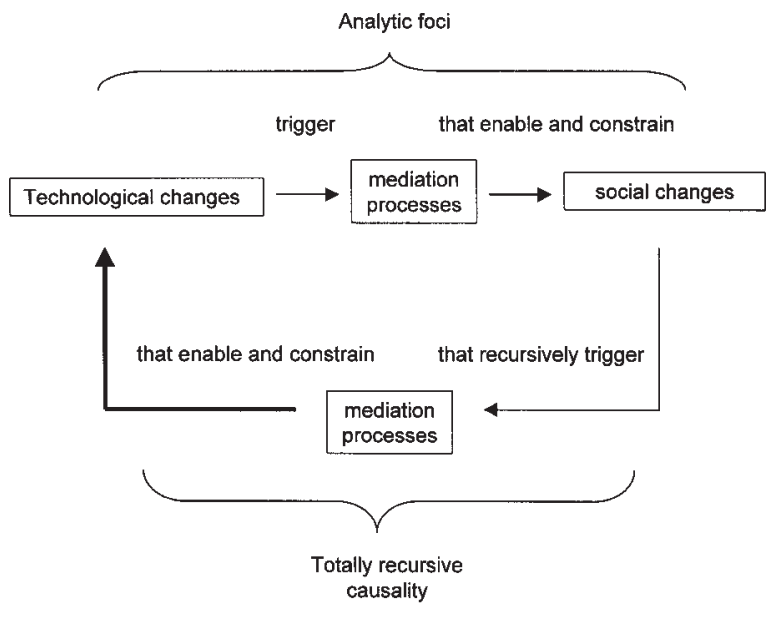

Main differences with Mediated Impact perspectives

Figure 3. Mutual shaping conceptualizations: relationships among the elements, forms of causality, and foci of the analysis

to, artifacts. These emerging approaches have stressed the mutual shaping of technological features and users' actions in CMC phenomena. A look at unfolding patterns in the study of technological change reveals closely related concerns.

\section{Multidisciplinary Examinations of Technological Change}

In recent decades, specialists in disciplines as diverse as communication, sociology, history, economics, and organization and innovation studies have emphasized that innovation does not stop when a given artifact is implemented, but rather continues throughout its use (Johnson \& Rice, 1987; Kline \& Pinch, 1996; Leonard-Barton, 1988; Rosenberg, 1982; Tyre \& Orlikowski, 1994; von Hippel, 1988). As Rice and Rogers (1980) said, "Reinvention can occur at any stage in the innovation process after the original agenda has been set" (p. 510). Empirical studies informed by this conceptual trend have revealed that users integrate new technologies into their daily lives in myriad ways. Sometimes they adapt to the constraints artifacts impose. On other occasions they react to them by trying to alter unsuitable technological configurations. Put differently, technologies' features and users' practices mutually shape one another.

The history of 20th-century media has provided highly informative illustrations of user-generated technological changes. Douglas (1988) has demonstrated how amateurs shaped the radio as the mass communication system that we know today, with the consequence that "the radio trust had to reorient its manufacturing priorities, its corporate strategies, indeed, its entire way of thinking about the technology under its control" (pp. 302-303). Moreover, Martin (1991) and Fischer 
(1992) have shown how early telephone callers, especially female callers, embedded "sociability" in the lines, thus pushing the telephone industry to introduce technical changes to what was originally conceived as a business tool. Finally, a more contemporary example can be found in the French Télétel videotex system, which is better known as the Minitel. Commentators like Charon (1987), Iwaasa (1988), and Marchand (1987) have documented how users turned Télétel-initially designed as a one-to-many information medium-into a many-to-many communication space through the emergence and growth of its popular messaging systems. As Feenberg (1992) noted, "in its final configuration, Télétel was largely shaped by the users' preferences" (p. 186). Thus, the history of some of this century's most important communication media lends credence to the scheme of the technology-user relationship represented in Figure 3.

Furthermore, analysts have argued that the capacity to change according to users' demands was a key factor behind the comparative success of the French videotex initiative vis-à-vis the British and German failures in the same arena (Mayntz \& Schneider, 1988; Miles, 1992). In this sense, the economic value of user-driven sociotechnical alterations should not be underestimated because, as Rosenberg stated (1982), "it is probably no accident that the industries that rely heavily on learning by using-aircraft, electric power generation, telephones and, more recently, computers-have had some of the most impressive productivity growth in the twentieth century" (p. 140). Analysts have suggested that these processes are even more relevant in the case of CMC devices, because they are becoming highly customizable, general-purpose tools adopted in mutable social settings. For instance, Orlikowski et al. (1995) stated that, "The sustained effectiveness of computer-mediated communication technologies in flexible new organizational forms will depend in great part on ensuring that the technologies are relevant to specific contexts of use, and that they continue to be relevant as those contexts change" (p. 424).

This overview of developments on the idea of users as agents of technological change has stressed an important conceptual issue: Artifacts are not only constructed by their designers, they are also reconstructed by their users. Artifacts' features enable and constrain certain types of social action, and users may either leave those features untouched or attempt to modify them. That is, the fact that users reconstruct the artifacts with which they interact does not mean that the latter will always change, but that, in principle, they are always subject to alterations. Whether an artifact remains the same or is modified during its use depends on local factors such as users' degree of satisfaction with the artifact as it is, the availability of symbolic and material resources to undertake transformative actions, the artifact's relative hardness, and its links to contextual factors.

Therefore, when studying technology-user relationships, neither the presence nor the absence of transformative attempts by the latter should be taken for granted. Rather, the presence or absence of transformations should be treated as a cultural achievement to be explained, if that is relevant for the goals of a particular inquiry. Similarly, the fact that any relatively stable technology is reconstructed during its use does not mean that the analyst has to deconstruct this process of reconstruction regardless of what question informs his or her study. Knowledge 
advances by foregrounding parts of a whole while maintaining the rest in the background. Otherwise, the complexity of social phenomena would make any research impossible. Thus, the crucial contribution of this constructionist view of technology-in-use is not that every user's reconstruction should always be analytically deconstructed, but that any one could be deconstructed if necessary.

Furthermore, these developments on users as agents of technological change have been part of a broader conceptualization of the relationship between artifacts and human beings. Often, scholars have espoused a relatively unilateral causal view. They have focused either on the social consequences of technological change or, most recently, on the social shaping of technological systems. Whereas the former have usually centered upon how technologies impact upon users' lives, the latter have tended to emphasize how designers embed social features in the artifacts they build. In this sense, the process of inquiry has fixed either the technological or the social, thus turning it into an explanans rarely problematized. However, what the study of technology-in-use has ultimately shown is that technological and social elements recursively influence each other, thus becoming explanans (the circumstances that are believed to explain the event or pattern) and explanandum (the event or pattern to be explained) at different periods in the unfolding of their relationships. It is to account for those patterns of recursive influence that concepts such as mutual shaping (Bijker, 1995), coproduction (Jasanoff, 1996; Latour, 1991), coevolution (Callon, 1986; Yates, 1993), and coconstruction (Fujimora, 1996) have been recently developed. Despite their different connotations, they have shared the general stance that social and material elements originate, endure, and decay as the result of situated relational processes of cultural construction.

To understand some of the local particularities in the AML case, I draw next from developments on the construction of national identities in everyday life.

\section{Social Psychological Analyses of Nationhood}

The origin and evolution of nation-states have played a crucial social, political, and economic role during the past centuries. Thus, it is not surprising that the study of them has figured prominently in the agenda of the humanities and social sciences (e.g., Anderson, 1991; Bhabha, 1990; Gellner, 1983; Giddens, 1985; Hobsbawn, 1990). Among other topics, the examination of nationalism has drawn considerable attention, revealing the significance that sharing national identities has in determining social action. As Anderson (1991) put it in defining the nation as an imagined political community, "ultimately it is this fraternity that makes it possible, over the past two centuries, for so many millions of people, not so much to kill, as willingly to die for such limited imaginings" (p. 7). However, nothing so radical happens in national virtual communities. Nobody kills or dies for participating in one of them. On the contrary, members of these distributed networks in cyberspace simply discuss the most ordinary national issues-politics, sports, cultural trends, and so on-albeit in not-so-ordinary circumstances: They are located all over the globe and conduct their discussions by electronic mail.

To understand the significance of ordinarily reconstructing national identities under less ordinary circumstances, I draw on recent work in the social psychology 
of nationhood. Seeking to move the study of nationalism from the periphery to the center-from "them" to "us" — and from special events to mundane acts-from wars to the common practices that constitute everyday life-Billig (1995) examined the mechanisms that almost invisibly reconstruct national identities in the ordinary social experiences of citizens of Western countries. Billig coined the term banal nationalism to refer to those "ideological habits which enable the established nations of the West to be reproduced ... [and which] are not removed from everyday life. .. . Daily, the nation is indicated, or 'flagged', in the lives of its citizenry" (p. 6). Thus, banal nationalism points to the role of taken-for-granted practices in making possible the emergence and maintenance of national identities.

Detailing Billig's (1995) complete approach exceeds the scope of this essay. Therefore, in the remainder of this section, I focus on three key issues of the dynamics of banal nationalism in the AML, in particular, and in any other national virtual community, in general. First, discursive elements have an important function in fostering a sense of "us" different from "them." Briefly stated, to have "a national identity is to possess ways of talking about nationhood" (Billig, 1995, p. 8). Moreover, the use of vernaculars tends to figure prominently as discursive resources of identification and identity construction (Anderson, 1991; Edwards, 1985; Snyder, 1976). Second, Billig (1995) emphasized that achieving a national identity "also involves being situated physically, legally, socially, as well as emotionally: typically, it means being situated within a homeland" (p. 8). That is, the subjective experience of nationhood is brought forth through social relationships that usually take place within the geographic boundaries of the nation-state. Finally, these discursive and territorial factors have an implicit character. Most of the time people are not aware of how their use of vernacular expressions and their location in concrete physical settings remind them of their nationality. To the contrary, these reminders "are so numerous and they are such a familiar part of the social environment, that they operate mindlessly, rather than mindfully. The remembering, not being experienced as remembering, is, in effect, forgotten" (Billig, 1995, p. 38).

In sum, to Billig (1995) the construction of national identities takes place through seemingly banal processes that constantly reinscribe in people's consciousness their national belongings. Moreover, these processes are almost effortless. They happen, at least partially, through sharing a repertoire of rather mundane discursive resources and inhabiting common territories where the symbolic and legal power of the nation-state is deployed in apparently meaningless situations.

To conclude, on the one hand, recent developments in social studies of CMC and in technology scholarship have emphasized the importance of understanding the mutual shaping of technological features and users' discourses and practices. On the other hand, Billig's (1995) work has shown how national identities emerge out of the fabric of everyday life. Moreover, the three contexts of inquiry have stressed the significance of local material and social factors in steering the course of events. This study contributes to these developments by showing how the members of the AML transformed and adapted to the technologies through which they interacted, and how these processes and products influenced, and were influenced by, their reconstructions of nationhood. In this sense, this study broad- 
ens the scope of both the technology-user relationship question in CMC (by addressing it in the context of a national virtual community) and the dynamics of banal nationalism (by studying it in a situation of territorial displacement in which communication happens in cyberspace).

\section{The Argentine Mailing List}

The AML is a mailing distribution list for people interested in Argentine issues. A mailing distribution list is an asynchronous one-to-many communication device, which distinguishes it from other types of CMC such as electronic mail (one-toone communication) and computer conferencing (many-to-many communication). To join a mailing list a person has to subscribe to it. Then he or she gets the messages automatically "into the same user interfaces that are used for ordinary [electronic] mail" (Quarterman, 1990, p. 14). Constant changes in the membership usually require the presence of a system operator (sysop).

The AML was founded in 1989 by a small group of people, and over the years it evolved into a larger community. As of November 1995 it had 1,412 members who called themselves coneteros/as - a word that loosely translates as co-netpeople. The popularity of the AML has even drawn the attention of the Argentine press (Lavieri, 1994; Rozenberg, 1994). Although the vast majority of coneteros/as were Argentine nationals living abroad, some others were either Argentine citizens in Argentina or foreigners interested in Argentina. Coneteros/as interacted mostly in Spanish. By the end of 1995, the AML was not the only Argentine "neighborhood" (Lewenstein, 1995) in cyberspace. A Usenet newsgroup called "soc.culture.argentina," the channel "\#argentina" in IRC, and the AML WWW server "Gardel" were other well-known Argentine sites.

Between 1989 and 1995 the AML administration and server shifted locations several times. For the past few years before 1995 they were based in a U.S. university, where the most recent sysop worked. As of November 1995 there were no criteria for screening membership. To become a conetero/a-a person sent a message of subscription to the AML's server, which handled the request automatically. The AML was divided into six "ordinary" sublists. A person could belong to as many as he or she wanted, but had to subscribe separately. The sublists were (a) Sports, where the exchange centered on soccer; (b) Literary corner, with an emphasis on Latin American literature; (c) Musical, a forum for talking about tango and Argentine folk and rock music; (d) Charter, where people exchanged information about flights to Argentina; (e) the Café, which tried to imitate the Argentine social practice of going to a café and talking about any kind of issues; and (f) News, which was devoted to information about current Argentine events. In addition to these ordinary sublists, there were two special sublists: (a) All, which was reserved for special announcements to reach all the members of the different sublists; and (b) the Council, a structure for debating issues about the functioning of the AML. Coneteros/as could receive the content of any sublist in two ways: each message separately, or a few large messages formed by all the discrete messages sent daily-which is called 


\section{Table 1. Membership Distribution per Sublist}

$\begin{array}{lrrr}\text { Sublist } & \text { Receiving separate messages } & \text { Receiving the packed } & \text { Total } \\ \text { Café } & 314 & 128 & 442 \\ \text { Sports } & 209 & 184 & 393 \\ \text { Literary corner } & 203 & 106 & 309 \\ \text { Musical } & 82 & 0 & 82 \\ \text { Charter } & 295 & 0 & 295 \\ \text { News } & 735 & 472 & 1207 \\ \end{array}$

Note. Because each conetero/a could subscribe to more than one sublist, the total AML membership was smaller than the sum of each sublist membership.

"the packed" (el empaquetado). ${ }^{2}$ Membership distribution in the ordinary sublists is shown in Table 1.

I did research on the AML from October 1994 to November 1995. After that period, I was a member for brief intervals and did not gather information (except where indicated in the following sections). During those 14 months I was a participant observer in all the ordinary sublists. As an Argentine national living abroad, I was interested in the public exchanges taking place in the network. I intervened in some of these exchanges, and also had private exchanges with other coneteros/ as. I collected data from the public exchanges_- "public" in the sense that they (a) were available to all the people who subscribed to the lists in which they took place and (b) the subscription process was automatic, so any person with access to electronic mail could potentially participate.

Once the data were collected, I did a qualitative content analysis of the messages that belonged to the different exchanges examined. Helped by my understanding of Argentine culture and my own experience as a migrant, I centered my analytic gaze on how technological features and users' discourses and practices related to each other, and how these relationships influenced and were influenced by coneteros/as' reconstructions of nationhood in cyberspace.

In the following two sections I report the results of this analysis. The first section concentrates upon the dynamics of mutual shaping in CMC, whereas the second focuses more on how these processes related to the particularities of banal nationalism in cyberspace. I have translated message fragments and concealed the identity of their authors.

\section{The Quest Toward Increased Technological Autonomy and Social Options}

During my study there were two changes in the software and one change in the hardware used by the AML, as well as steps toward a second hardware modification (discussed later in this essay). In the first software change, Majordomo ${ }^{\mathrm{TM}}$ (a program for electronic mail distribution that, at that time, was widely used by

${ }^{2}$ Similar to what is called a "digest" in listserv parlance. 
electronic mailing lists) was introduced to automate several sysop's tasks (e.g., subscription of new members and requests for shifting among sublists). It was thought that an increased degree of automation would speed up the distribution process and improve the flow of messages. However, things did not happen as expected. Adopting Majordomo ${ }^{\mathrm{TM}}$ taxed the server's memory and created many duplicated messages. This led to complaints and to a paradoxical growth in the sysop's work.

Overwhelmed by the situation created after the introduction of Majordomo ${ }^{\mathrm{TM}}$, the sysop sent messages communicating her feelings of stress and calling for volunteers to assist her in making decisions about technical issues. Then, two unforeseen processes happened. First, a new social structure-the Councilemerged with about a dozen coneteros/as who offered to help keep the list functioning well. Initially the Council dealt mostly with technical matters, but it rapidly evolved into a general advisory board covering social issues as well. ${ }^{3}$ Second, triggered by the sysop's idea of sharing administrative duties, some coneteros/as conceived a plan to buy AML's own hardware and software. Because the server from which the network was administered belonged to the sysop's workplace, it was difficult for the sysop to share her root password with other coneteros/as. This had the consequence of leaving her in a central position within the administrative design. However, a group of coneteros/as generated an ambitious proposal: What if the AML bought its own machine? In the words of one of its proponents,

The goal is to obtain hardware powerful enough to cover without difficulty the growing needs-because the number of subscribers is also growing —of the distribution list and at the same time host other parallel activities that have been developing within the context of this network, such as the WWW servers, the online transmission of soccer games, the development of the CDROM—Morel's Café [which will be analyzed later]—and many others.

According to initial calculations, the machine would cost around $\$ 8,000$. Given the expense, the group of people who came up with the original idea (who soon became an informal "project team") sent a message to all members explaining the initiative and asking how many would donate around $\$ 20$ to purchase the equipment. The machine would be initially located at the sysop's workplace and would not interfere with her job, thus making possible a "virtual" administration. Also, being exclusively used by the AML, the new server would speed up message flow and make it easier to produce other technical features.

After receiving more than 400 affirmative responses to the call for potential contributors, the team designed the fund-raising campaign. Nine coneteros/as would act as "money boxes" [alcancías]: three for the United States, three for Europe, and one each for Latin America, the Middle East, and the Pacific region.

\footnotetext{
3 This development in the AML social structure has interesting parallels with processes described in other CMC contexts (Orlikowski, Yates, Okamura, \& Fujimoto, 1995) and raises important questions about the characteristics of democratic processes in cyberspace (Bruckman \& Resnick, 1995; Curtis, 1992; Kollock \& Smith, 1994; Smith, 1992; Stone, 1995).
} 
Each money box had to collect the money from its region, convert the final sum to U.S. currency, and send it to a person to be designated afterward. To verify the information, and make the whole process as transparent as possible, each money box would periodically send the Café a list with the contributors' names and the amount donated. As of November 1995, the fund-raising campaign was nearly complete. Almost \$7,000 was collected. More than 300 coneteros/as had contributed, and the Council was discussing machine choices, future server locations, and administrative alternatives. Some months later the new server was installed. As a result of a public election, it was given the name Mafalda, after one of the most popular Argentine cartoon characters.

What does the unfolding of this quest toward increased machine autonomy and administrative decentralization tell us about the relationships between technological features and users' actions in CMC? Figure 4 illustrates the application of the mutual shaping perspective presented above. The process began with the constraints that existing hardware availability imposed upon the sysop's job. This, in turn, limited social practices, such as the exchange of the usual message flow, and added features such as the possibility of transmitting soccer games. The character of these constraints should not be underemphasized because they touch upon the network's daily functioning and the character of banal nationalism. Given the function that soccer has in the socialization of many Argentine people, accessing the transmission of a game while living abroad plays a significant role in the reconstruction of many coneteros/as' national identities.

Driven by the perceived unsuitability of the CMC technologies through which they interacted, users reacted by searching for appropriate transformative measures. They did so by promoting a change in a key component of the network's infrastructure: the software used for electronic message distribution. However, the introduction of Majordomo ${ }^{\mathrm{TM}}$ did not result as planned. It further constrained both the sysop's job and coneteros/as' communication practices. This impacted negatively upon the AML's daily functioning. That new stage of social dissatisfaction triggered another round of deliberation, which ended up generating a highly significant change in the network's social structure and a very ambitious goal (i.e., creation of the Council and the plan of buying a server to be owned by the AML instead of by the sysop's workplace, respectively). These social outcomes triggered yet another round of mediation processes embodied in the fund-raising campaign, which finally led to the acquisition of the new machine.

How can we best account for the relationships between technological and social elements that took place in the events described in this section? On the one hand direct- and mediated-impact perspectives would have missed the diverse ways in which coneteros/as sought to alter the hardware and software used by the AML. On the other hand, social shaping approaches would have overlooked the different ways in which existing technological features facilitated and limited the scope of social action. Moreover, these approaches would have missed the dynamic interaction between artifacts' enabling and constraining social discourse and practice, and people's various adaptive and transformative actions with respect to those very same artifacts. Thus, it is my contention that a mutual shaping perspective best captures the recursive and evolving manner in which building 
limits

which constrains

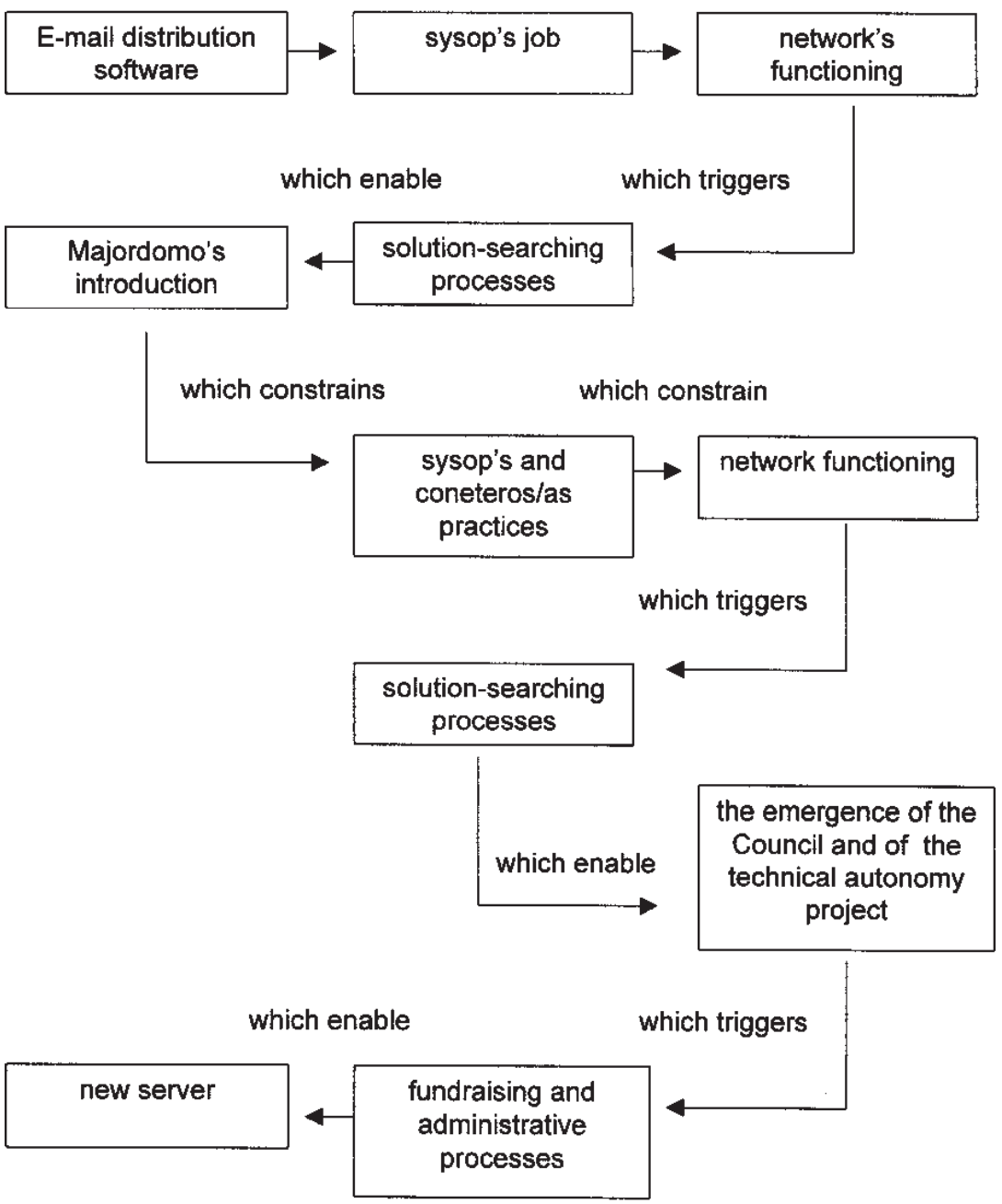

Figure 4. Graphical representation of mutual shaping processes leading to the acquisition of the new server

increased technological autonomy, and promoting decentralized administrative designs and wider social engagements were all products of the same relational processes.

It is worth noting how the coordination practices enacted to acquire the new machine mirrored the distributed nature of the network's infrastructure. The physical dispersion of those collecting the money replicated the geography of machinery location (with the exception of the server's location). In this sense, the global nature of the AML was relationally reconstructed among and across various ele- 
ments of the network (i.e., the technology, the goal of a less territorially bounded administration, and the coordination strategies created to carry on the changes).

Furthermore, the new server's name points to the banal nationalism that was partially both engine and outcome of this recursive relationship between technological features and users' actions. Mafalda is a cartoon character that originated in Argentina in the 1960s and still remains very popular, cutting across age and class differences. Despite its international success (the cartoon has become a syndicated feature published in various Latin America and European outlets), Argentine people see Mafalda as part of their national cultural landscape. By calling the new machine Mafalda, coneteros/as embodied yet one more attribute of nationality in a crucial piece of the infrastructure through which they interacted. This decision reinforced their sense of national belonging. To expand on these matters, I next discuss the particularities of banal nationalism in the mutual shaping of users and technologies in cyberspace.

\section{Planning an Artifact, Talking a Nation}

In the AML, conversations about memories abound. They often trigger reflections on the nature of the network and on the particularities of constructing nationality in cyberspace. On one particular occasion, these conversations got tied up with coneteros/as' attempts to build a new artifact. Over the course of the AML's existence, some coneteros/as had collected photographs of its members. One call for new contributions generated the project of turning these pictures into a multimedia object. The idea rapidly attracted coneteros/as' attention and generated a discussion about the nature of the platform. One group of people proposed building a hypermedia document on the World Wide Web that could be periodically updated at low cost. Another group suggested constructing a CD-ROM and gave two reasons for that choice: The idea was to "immortalize" a moment in the evolution of the network (which ruled out the need for updates), and it was presumed that, whereas only a small portion of coneteros/as had Internet access, many more had CD-ROM drives. The two groups engaged in a process of "interpretive flexibility" (Pinch \& Bijker, 1984) in which they espoused different meanings about what the artifact should be, thus about the best technical platform. After several exchanges, coneteros/as settled on the idea of using a CD-ROM for two major reasons: its higher penetration and the greater familiarity with the technology within the AML at that time, even at the expense of its decreased flexibility vis-à-vis a Web page. ${ }^{4}$

Shortly after the decision about the platform was made, a group took on the project's coordination. One of its tasks was to organize the selection of the CDROM's name. They did this by holding an election. The winner was Morel's Café, which paid tribute to Argentine novelist Adolfo Bioy Casares's 1964 novel, The Invention of Morel. In this novel a fugitive arrives on an island inhabited by a group of people who repeat their actions each week in a cyclical fashion, and

\footnotetext{
${ }^{4}$ I would like to thank one of the reviewers for calling my attention to this point.
} 
who act as if the fugitive is invisible to them. After some time, the fugitive discovers that these people are dead, and that what he sees are images projected by a machine invented by a character called Morel. The machine recorded the life of these people during a week, but killed them by doing it. The name Morel's Café was advertised as celebrating the first virtual reality machine. But another aspect of the novel was also central to the CD-ROM endeavor, and to the very raison d'être of national virtual communities: the dialectic between memory, materiality, and immortality. In Bioy Casares's (1964) prescient words,

I believe we lose immortality because we have not conquered our opposition to death; we keep insisting on the primary, rudimentary idea: that the whole body should be kept alive. We should seek to preserve only the part that has to do with consciousness. (p. 14)

The importance of this dialectic between materiality, memory, and immortality in the mutual shaping of technological features and users' identities was evident throughout the discussions around Morel's Café. Talking about the construction of the CD-ROM rapidly became a vehicle for perpetuating nationhood. Conversations often started addressing issues directly pertaining to building the CD-ROM and rapidly shifted to processes of "conversationally remembering" (Middleton \& Edwards, 1990) different cafés coneteros/as felt linked to diverse moments of their lives. That is, what began as discussions about the CD-ROM's content and form tended to turn toward exchanges about experiences and memories about cafés and café culture. As one conetero put it: "The descriptions by X [awakened] my memories of the neighborhood cafés. . . I'm not sure that these memories serve to enrich the CD-ROM, but I enjoyed sharing them."

Moreover, as if every café could become all cafés in these processes of conversational remembering, another conetero sent a fragment of chapter 132 of Argentine novelist Julio Cortázar's 1966 novel, Hopscotch, which begins:

And while somebody explains something as always, I don't know why I am in this café, in all cafés, in the Elephant \& Castle, in the Dupont Barbès, in the Sacher, in the Pedrocchi, in the Gijón, in the Greco, in the Café de la Paix, in the Café Mozart, in the Florian, in the Capoulade, in Les Deux Magots. (p. 510)

After naming many other cafés, Cortázar (1966) continued:

In cafés anywhere where[:]

We make our meek adjustments,

Contended with such random consolations

As the wind deposits

In slithered and too ample pockets.

Hart Crane dixit. But they're more than that, they are the neutral territory for the stateless of the soul. (emphasis added; p. 510)

This joint evocation of material places and symbols of nationhood was also tied to sharing stories about childhood, dreams, and migration (as had happened pre- 
viously in the networks' evolution). For example, on one occasion a game was devised in which coneteros/as were asked to tell something about themselves. Soon after the game started, a flurry of deeply emotional stories populated the exchanges, which led one conetera to say, "Rilke said that perhaps one does not belong to any country but to that of her/his childhood, which equals establishing a space-time continuum within our particular destinies. Sometimes I believe so."

In the AML these processes of collective remembering were tied to talking about national issues. In the present case, coneteros/as embodied these processes in the planned content of the CD-ROM, which then became a symbol of nationality. Thus, mirroring Cortázar's (1966) depiction, Morel's Café was imagined as an infinite babel composed of furniture and other objects, social roles and stereotypes, magazines and newspapers, foods and beverages, posters and paintings, bathroom graffiti, and conversation topics drawn from a myriad of real and imaginary cafés attached to meaningful moments of coneteros/as' lives. ${ }^{5}$ As of November 1995, Morel's Café was still under construction.

How are we to understand the technology-user relationship in building this artifact of nationhood? It is my contention that the dynamics of banal nationalism energized the mutual shaping of users and technologies that brought forth Morel's Café, and that its planning and initial stages of development subsequently influenced coneteros/as' subjective experience of nationhood in cyberspace. That is, Morel's Café emerged out of a mutual shaping of an array of material and social elements-from technological platforms to childhood memories-and became an evocative object (Turkle, 1984), triggering reflective processes about issues of national identity and its relationships to the network. For example, one conetero reflected upon the role of belonging to the AML and his subjective construction of nationhood in the following way:

It's been more than three years since I lived abroad and was connected to the network. This is the first time I write . . . [since] the virtual café made me re-think many things. One of them is why . . . I didn't write before? And I think I didn't do it before because it always seemed to me that I was abroad only "circumstantially," and for this reason I looked at "the thing from the outside" [la cosa desde afuera]. [A couple of months ago] I was in Argentina and felt more than ever a kind of exile syndrome in which one looks for spaces, people and a country that aren't there. It's anguishing and bewildering. That's why it seems to me that the café is also this, a place ... where one finds oneself.

In another message, a conetero communicated somewhat different views on the subjective role of the network: "The network functions like a balm, confirming that one's own identity is there, far away and untouched, and that it's enough to go back in order to put it on [ponérsela] like and old and comfortable suit." Through these reflective processes, coneteros/as engraved nationality in the planned artifact and in the texture of their social and personal experiences. Objects,

\footnotetext{
${ }^{5}$ In this sense, Morel's Café became a representation without an original, a simulacrum (Baudrillard, 1983), which is a notion that has been variously tied to the study of CMC phenomena (Poster, 1990, 1995; Turkle, 1995).
} 
subjectivities, and conversations became so deeply intertwined that any one of them could not easily be conceived without the others. It is this intimate connection-and the relational, recursive, and coevolving process that brings it forththat would not be captured by adopting the mostly linear causal matrix of either the technology's impact or social shaping perspectives.

By acting as an evocative object, the development of Morel's Cafe became a forum that made the enactment of banal nationalism in cyberspace more visible. Morel's Café embodied the routines tied to the café as a social institution, with the consequence of reaffirming the subjective presence of the Argentine nation among coneteros/as. In a conetera's words:

With so many years in the United States it's a pleasure for me to be in contact with this group of fellow nationals who informs and thinks about what happens in the country [referring to Argentina]; in its rare mixture of wise and suicidal people [sabiondos y suicidas, a phrase that alludes to the lyrics of a popular tango written using some vernacular expressions], the network is like a window to the corner's café [el café de la esquina, another popular Argentine phrase]—which moved from tin to plastic and now to cyberspace.

This conetera's evocation of tango lyrics that have words and phrases typical of how Spanish is spoken in Argentina is worth noting. How, though, do the semiotic factors so central to the unfolding of banal nationalism fare in a situation of discursive displacement? Most coneteros/as live in places where the use of Argentine vernacular is out of context. The use of vernacular expressions was very common during my study and was also the subject of repeated debates. This should come as no surprise, given the role that Billig (1995) and others have assigned to language in the creation and maintenance of nationhood. Often coneteros/as discussed the importance that being in touch with "their" language had for their psychological well-being and for reminding them of their origins. It is my contention that banal nationalism in national virtual communities takes place, at least partially, through heightening the use of those discursive markers that distinguish one national group from the others and through making their use a matter of public discussion. In a sense, it is as if coneteros/as compensate for their semiotic deprivations in everyday life by increasing their attention on Argentine discursive resources and the frequency of their use.

Furthermore, a related question arises: How does the diasporic situation of most coneteros/as relate to the unfolding of banal nationalism in cyberspace? In a development that mirrors what happens with semiotic resources, deterritorialization leads to an intensification in the explicit processes of collective remembering in a context like the AML. This is expressed, for example, in the repetition of conversations about memories of strong Argentine content. In Morel's Café, this is illustrated in the shift from discussions on the CD-ROM's content to dialogues about café stories-which later became embedded in exchanges planning the actual CD-ROM.

The key distinction is not between presence or absence of using vernacular expressions and sharing childhood memories, but between their explicit or implicit character and frequency of occurrence. Citizens of established nations who 
live in their homelands are reminded of their nationhood in an implicit fashion through events, artifacts, and signs scattered in the background of their activities. By contrast, deprived of a physical anchorage within the Argentine territory, most coneteros/as repeatedly engage in intensified and explicit practices of collective remembering and discursive sensitization. Far from being buried in their daily routines, the construction of banal nationalism is inscribed in the very surface of their electronic experiences. Perhaps nothing summarizes this movement from what is implicit and in the background to a more explicit articulation and a foreground position than one conetera's words:

Let me explain why I suggested the name "Los enredados" [The intertwined] for our café and CD-ROM. . . . We ARE INTERTWINED: when we wake up in the morning and go to see what's in the mail, and go again two hours later, in the afternoon, and before going to bed at night. . . . Moreover, "Los en redados" [emphasis added] has a lot to do with the net and "red" [net] is closer to our languages than net, which is a little bit more correct than using English words for an Argentine Café.

To sum up, Morel's Café emerged from the mutual shaping of a wide array of technological and social elements combined with the dynamics of banal nationalism in cyberspace. The CD-ROM project did not directly arise out of the desire to preserve nationhood. However, after it began, the very same processes that shaped the technology were driven by issues of national identity, and planning the artifact influenced coneteros/as' national representations. In this sense, banal nationalism in cyberspace simultaneously became the means and ends of coevolving ensembles of technological and material entities that constitute the AML. Finally, the particularities of reconstructing nationhood in situations of territorial and discursive displacements were enacted in both coneteros/as' shaping of the CD-ROM and Morel's Café's shaping of their identities.

\section{Conclusion}

How did technological features and users' discourse and practices relate to each other during the above analyzed episodes in the AML's life? First, they were connected through a host of mutual shaping processes between the seemingly disparate domains of increased hardware and software capabilities and decentralized administrative design, and technological planning and identity construction. Second, that mutual shaping of technological and social elements was strongly influenced by the dynamics of banal nationalism, as transformative actions were fueled by issues charged with national significance. In a recursive fashion, these actions energized the relational processes through which users' subjective representations of nationhood were reconstructed. Third, the interpenetration of mutual shaping and banal nationalism in cyberspace showed that, in a situation of territorial displacement, collective rememberings and vernacular expressions acquired a more explicit and intensive character than they feature under more usual circumstances. 
Therefore, the analysis presented in this essay contributes to accomplishing the dual conceptual goal stated at the end of the theory section. On the one hand, it broadens our understanding of the technology-user relationship in CMC by examining the dynamics of mutual shaping in the case of a national virtual community. On the other hand, it deepens our knowledge of banal nationalism by exploring its dynamics in a migratory group scattered all over the planet and in which actors relate to each other in and through CMC.

Furthermore, because much scholarship in the social study of CMC is wedded to either social impact or social shaping perspectives, I want to stress that a mutual shaping perspective is best suited to capture the complexity, unpredictability, and recursivity of what goes on in a communication environment such as the AML. On the one hand, a social impact approach would be appropriate to describe the technology's role in enabling and constraining users' actions, but might miss their transformative endeavors. On the other hand, a social shaping approach would adequately portray users as agents of technological change, but might overlook the significance of artifacts' effects on social life. Adopting a mutual shaping approach does not imply rejecting the contributions of social shaping or social impact perspectives. It includes them within a broader and more heuristically powerful conceptual framework. Moreover, and probably due to the unidirectional emphases of their respective conceptual foci, social impact and social shaping approaches are conceptually better equipped to explain the products rather than the processes of CMC, something especially limiting in the case of a national virtual community, which evolves over time, and where changes happen at many stages in the unfolding of the technology-user relationship.

To what extent can these conclusions be applied to other CMC situations? At a conceptual level, mutual shaping perspectives offer a more comprehensive and flexible framework than technology's impact and social shaping approaches. They are more comprehensive because they consider the influence of more elements and their relationships over time. They are more flexible because they do not set the explanans a priori, but let the researcher find it through the process of inquiry. This does not mean that in every context of CMC, users and devices will transform each other. However, the analyst is able to apply the same conceptual tools to explain situations of change and of permanence. At a more empirical level, this essay points to the importance of identity factors as both attractors and outcomes of CMC engagements. In those cases communication practices over computer networks move from the instrumental realm to the domain of people's subjective representations of who they are. In such a situation the variety and intensity of coneteros/as' behaviors geared toward establishing a more suitable material environment for their electronic experiences is not surprising. In that sense, it is possible that the same type of transformative practices could be found in other identity-driven CMC groups, based in a wide array of traits ranging from lifestyle choices to situations of chronic illnesses. Only future comparative studies will reveal whether that is the case, and how communication practices in those groups relate to more instrumental uses of CMC capabilities as can be found, for instance, in many workplace situations. 


\section{References}

Anderson, B. (1991). Imagined communities. (2nd ed.). London: Verso.

Baudrillard, J. (1983). Simulations. New York: Semiotext(e).

Baym, N. (1995). The emergence of community in computer-mediated communication. In S. Jones (Ed.), Cybersociety: Computer-mediated communication and community (pp. 138-163). Thousand Oaks, CA: Sage.

Bhabha, H. (1990). Introduction. In H. Bhabha (Ed.), The nation and narration (pp. 1-7). London: Routledge.

Bijker, W. (1995). Of bicycles, bakelites, and bulbs: Toward a theory of sociotechnical change. Cambridge, MA: MIT Press.

Billig, M. (1995). Banal nationalism. London: Sage.

Bioy Casares, A. (1964). The invention of Morel and other stories. (R. Simms, Trans.). Austin: University of Texas Press. (Original work published 1940)

Bruckman, A., \& Resnick, M. (1995). The MediaMOO project: Constructionism and professional community. Convergence, 1(1), 94-109.

Callon, M. (1986). The sociology of an actor-network: The case of the electric vehicle. In M. Callon, J. Law, \& A. Rip (Eds.), Mapping the dynamics of science and technology: Sociology of science in the real world (pp. 19-34). London: Macmillan.

Charon, J. M. (1987). Videotex: From interaction to communication. Media, Culture E Society, 9, 301332.

Cortázar, J. (1966). Hopscotch (G. Rabassa, Trans.). New York: Pantheon. (Original work published 1963)

Curtis, P. (1992). Mudding: Social phenomena in text-based virtual realities. In D. Schuler (Ed.), DIAC2: Directions and implications of advanced computing (pp. 44-68). Palo Alto, CA: Computer Professionals for Social Responsibility.

Daft, R., \& Lengel, R. (1986). Organizational information requirements, media richness and structural design. Management Science, 32, 554-571.

Daft, R., Lengel, R., \& Trevino, L. (1987). Message equivocality, media selection, and manager performance: Implications for information systems. MIS Quarterly, 11, 355-366.

DeSanctis, G., \& Poole, M. S. (1994). Capturing the complexity in advanced technology use: Adaptive structuration theory. Organization Science, 5, 121-147.

Douglas, S. (1988). Inventing American broadcasting, 1899-1922. Baltimore: Johns Hopkins University Press.

Dubrovsky, V., Kiesler, S., \& Sethna, B. (1991). The equalization phenomenon: Status effects in computer-mediated and face-to-face decision-making groups. Human-Computer Interaction, 6, 119-146.

Edwards, J. (1985). Language, society and identity. Oxford, UK: Basil Blackwell.

Feenberg, A. (1992). From information to communication: The French experience with videotex. In M. Lea (Ed.), Contexts of computer-mediated communication (pp. 168-187). London: HarvesterWheatsheaf.

Feenberg, A. (1993). Building a global network: The WBSI experience. In L. Harasim (Ed.), Global networks (pp. 185-197). Cambridge, MA: MIT Press.

Finholt, T., \& Sproull, L. (1990). Electronic groups at work. Organization Science, 1, 41-64. 
Fischer, C. (1992). America calling: A social history of the telephone to 1940. Berkeley: University of California Press.

Fujimora, J. (1996). Crafting science: A sociobistory of the quest for the genetics of cancer. Cambridge, MA: Harvard University Press.

Fulk, J., \& Boyd, B. (1991). Emerging theories of communication in organizations. Journal of Management, 17, 407-446.

Fulk, J., Steinfield, C., Schmitz, J., \& Power, J. G. (1987). A social information processing model of media use in organizations. Communication Research, 14, 529-552.

Garton, L., \& Wellman, B. (1995). Social impacts of electronic mail in organizations: A review of research literature. Communication Yearbook, 18, 434-453.

Gellner, E. (1983). Nations and nationalism. Ithaca, NY: Cornell University Press.

Giddens, A. (1985). The nation-state and violence. Cambridge, UK: Polity Press.

Hobsbawn, E. (1990). Nations and nationalisms since 1780. Cambridge, UK: Cambridge University Press.

Iwaasa, R. (1988). Convivial messaging systems: Startling facts and figures about electronic mail (messageries) for French households. Information Society, 5, 265-269.

Jackson, M. (1996). The meaning of "communication technology": The technology-context scheme. Communication Yearbook, 19, 229-267.

Jasanoff, S. (1996). Beyond epistemology: Relativism and engagement in the politics of science. Social Studies of Science, 26, 393-418.

Johnson, B., \& Rice, R. (1987). Managing organizational innovation: The evolution from word processing to office information systems. New York: Columbia University Press.

Kiesler, S., \& Sproull, L. (1992). Group decision making and communication technology. Organizational Behavior and Human Decision Processes, 52, 96-123.

Kline, R., \& Pinch, T. (1996). Users as agents of change: The social construction of the automobile in the rural United States. Technology and Culture, 37, 763-795.

Kling, R., \& Scacchi, W. (1982). The web of computing: Computer technology as social organization. Advances in Computers, 21, 1-90.

Kollock, P., \& Smith, M. (1994). Managing the virtual commons: Cooperation and conflict in computer communities. Unpublished manuscript, University of California at Los Angeles.

Latour, B. (1991a). Technology is society made durable. In J. Law (Ed.), A sociology of monsters: Essays on power, technology and domination (pp. 103-131). London: Routledge.

Lavieri, O. (1994, April 10). Un argentino en tu compu [An Argentine in your computer]. Clarín, p. B-16.

Lea, M., O'Shea, T., \& Fung, P. (1995). Constructing the networked organization: Content and context in the development of electronic communications. Organization Science, 6, 462-478.

Lea, M., \& Spears, R. (1995). Love at first byte? Building personal relationships over computer networks. In J. Wood \& S. Duck (Eds.), Under-studied relationships: Off the beaten track (pp. 197-233). Thousand Oaks, CA: Sage.

Leonard-Barton, D. (1988). Implementation as mutual adaptation of technology and organizations. Research Policy, 17, 251-267.

Lewenstein, B. (1995). Do public electronic bulletin boards help create scientific knowledge?: The cold fusion case. Science, Technology, \& Human Values, 29, 123-149. 
Li, T. (1990). Computer-mediated communications and the Chinese students in the U.S. Information Society, 7, 125-137.

Marchand, M. (1987). La grande aventure du Minitel [The great Minitel adventure]. Paris: Larousse.

Markus, M. L. (1987). Toward a "critical mass" theory of interactive media: Universal access, interdependence and diffusion. Communication Research, 14, 491-511.

Martin, M. (1991). "Hello central?": Gender, technology and culture in the formation of telephone systems. Montreal, Canada: McGill-Queen's University Press.

Mayntz, R., \& Schneider, V. (1988). The dynamics of system development in a comparative perspective: Interactive videotex in Germany, France and Britain. In R. Mayntz \& T. Hughes (Eds.), The development of large technical systems (pp. 263-298). Boulder, CO: Westview Press.

Middleton, D., \& Edwards, D. (1990). Conversational remembering: A social psychological approach. In D. Middleton \& D. Edwards (Eds.), Collective remembering (pp. 23-45). London: Sage.

Miles, I. (1992). When mediation is the message: How suppliers envisage new markets. In M. Lea (Ed.), Contexts of computer-mediated communication (pp. 145-167). London: Harvester-Wheatsheaf.

Mitra, A. (1996). Nations and the Internet: The case of a national newsgroup, 'soc.cult.indian.' Convergence, 2(1), 44-75.

Ogan, C. (1993). Listserver communication during the Gulf War: What kind of medium is the electronic bulletin board? Journal of Broadcasting E Electronic Media, 37, 177-196.

Orlikowski, W. (1992). The duality of technology: Rethinking the concept of technology in organizations. Organization Science, 3, 397-427.

Orlikowski, W., \& Robey, D. (1991). Information technology and the structuring of organizations. Information Systems Research, 2, 143-169.

Orlikowski, W., \& Yates, J. (1994). Genre repertoire: The structuring of communicative practices in organizations. Administrative Science Quarterly, 39, 541-574.

Orlikowski, W., Yates, J., Okamura, K., \& Fujimoto, M. (1995). Shaping electronic communication: The metastructuring of technology in the context of use. Organization Science, 6, 423-444.

Pinch, T., \& Bijker, W. (1984). The social construction of facts and artefacts: Or how the sociology of science and the sociology of technology might benefit each other. Social Studies of Science, 14, 399441.

Poole, M. S., \& DeSanctis, G. (1990). Understanding the use of group decision support systems: The theory of adaptive structuration. In J. Fulk \& C. Steinfield (Eds.), Organizations and communication technology (pp. 173-193). Newbury Park, CA: Sage.

Poster, M. (1990). The mode of information. Chicago: University of Chicago Press.

Poster, M. (1995). The second media age. Cambridge, UK: Polity Press.

Quarterman, J. (1990). The matrix: Computer networks and conferencing systems worldwide. Bedford, MA: Digital Press.

Rai, A. (1995). India on-line: Electronic bulletin boards and the construction of a diasporic Hindu identity. Diaspora, 4, 31-57.

Rice, R. (1987). Computer-mediated communication and organizational innovation. Journal of Communication, 37(4), 65-94.

Rice, R. (1992). Contexts of research on organizational computer-mediated communication. In M. Lea (Ed.), Contexts of computer-mediated communication (pp. 113-144). London: Harvester-Wheatsheaf. 
Rice, R., \& Rogers, E. (1980). Reinvention in the innovation process. Knowledge, 1, 499-514.

Rosenberg, N. (1982). Inside the black box: Technology and economics. New York: Cambridge University Press.

Rozenberg, L. (1994, October 29). Café virtual a la criolla [Creole virtual café]. Página/12, Futuro, p. 4.

Short, J. (1974). Effects of medium of communication on experimental negotiation. Human Relations, $27,225-324$.

Short, J., Williams, E., \& Christie, B. (1976). The social psychology of telecommunication. Chichester, UK: Wiley.

Siegel, J., Dubrovsky, V., Kiesler, S., \& McGuire, T. (1986). Group processes in computer-mediated communication. Organizational Behavior and Human Decision Processes, 37, 157-187.

Smith, M. (1992). Voices from the WELL: The logic of the virtual commons. Unpublished master's thesis, University of California, Los Angeles.

Snyder, L. (1976). Varieties of nationalism: A comparative study. Hinsdale, IL: Dryden Press.

Spears, R., \& Lea, M. (1992). Social influence and the influence of the "social" in computer-mediated communication. In M. Lea (Ed.), Contexts of computer-mediated communication (pp. 30-65). London: Harvester-Wheatsheaf.

Sproull, L., \& Kiesler, S. (1991). Connections: New ways of working in the networked organization. Cambridge, MA: MIT Press.

Steinfield, C. (1992). Computer-mediated communications in organizational settings: Emerging conceptual frameworks and directions for research. Management Communication Quarterly, 5, 348365 .

Stone, A. R. (1995). The war of desire and technology at the close of the mechanical age. Cambridge, MA: MIT Press.

Trevino, L., Lengel, R., Bodensteiner, W., Gerloff, E., \& Muir, N. (1990). The richness imperative and cognitive style: The role of individual differences in media choice behavior. Management Communication Quarterly, 4(2), 176-197.

Turkle, S. (1984). The second self. New York: Simon \& Schuster.

Turkle, S. (1995). Life on the screen. New York: Simon \& Schuster.

Tyre, M., \& Orlikowski, W. (1994). Windows of opportunity: Temporal patterns of technological adaptations in organizations. Organization Science, 5, 98-118.

von Hippel, E. (1988). Sources of innovation. New York: Oxford University Press.

Walther, J. (1996). Computer-mediated communication: Impersonal, interpersonal, and hyperpersonal interaction. Communication Research, 23, 3-43.

Yates, J. (1993). Co-evolution of information-processing technology and use: Interaction between the life insurance and tabulating industries. Business History Review, 67, 1-53.

Yates, J., \& Orlikowski, W. (1992). Genres of organizational communication: A structurational approach to studying communication and media. Academy of Management Review, 17, 299-326. 